\title{
RESEARCH
}

\section{Vitamin D is crucial for maternal care and offspring social behaviour in rats}

\author{
Nathanael J Yates', Dijana Tesic', Kirk W Feindel2, Jeremy T Smith1, Michael W Clarke, Celeste Wale', \\ Rachael C Crew', Michaela D Wharfe', Andrew J O Whitehouse ${ }^{4}$ and Caitlin S Wyrwoll1 \\ 1School of Human Sciences, The University of Western Australia, Perth, Australia \\ ${ }^{2}$ Centre for Microscopy, Characterisation and Analysis, The University of Western Australia, Perth, Australia \\ ${ }^{3}$ Metabolomics Australia, Centre for Microscopy, Characterisation and Analysis, The University of Western Australia, Perth, Australia \\ ${ }^{4}$ Telethon Kids Institute, The University of Western Australia, Perth, Australia \\ Correspondence should be addressed to C S Wyrwoll: caitlin.wyrwoll@uwa.edu.au
}

\section{Abstract}

Early life vitamin D plays a prominent role in neurodevelopment and subsequent brain function, including schizophrenic-like outcomes and increasing evidence for an association with autism spectrum disorder (ASD). Here, we investigate how early life vitamin D deficiency during rat pregnancy and lactation alters maternal care and influences neurodevelopment and affective, cognitive and social behaviours in male adult offspring. Sprague-Dawley rats were placed on either a vitamin $D$ control $(2195 \mathrm{IU} / \mathrm{kg})$ or deficient diet $(0 \mathrm{IU} / \mathrm{kg})$ for five weeks before timed mating, and diet exposure was maintained until weaning of offspring on postnatal day (PND) 23. MRI scans were conducted to assess brain morphology, and plasma corticosterone levels and neural expression of genes associated with language, dopamine and glucocorticoid exposure were characterised at PND1, PND12 and 4 months of age. Compared to controls, vitamin D-deficient dams exhibited decreased licking and grooming of their pups but no differences in pup retrieval. Offspring neurodevelopmental markers were unaltered, but vitamin D-deficient pup ultrasonic vocalisations were atypical. As adults, males that had been exposed to vitamin $D$ deficiency in early life exhibited decreased social behaviour, impaired learning and memory outcomes and increased grooming behaviour, but unaltered affective behaviours. Accompanying these behavioural changes was an increase in lateral ventricle volume, decreased cortical FOXP2 (a protein implicated in language and communication) and altered neural expression of genes involved in dopamine and glucocorticoid-related pathways. These data highlight that early life levels of vitamin $D$ are an important consideration for maternal behavioural adaptations as well as offspring neuropsychiatry.

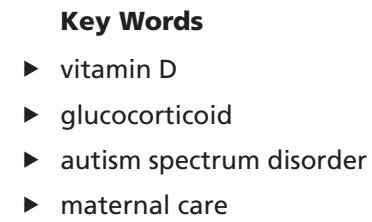

Journal of Endocrinology (2018) 237, 73-85

\section{Introduction}

The quality of early life environment is a powerful determinant of adult health outcomes, including brain function (Cottrell \& Seckl 2009). The abundant expression of vitamin D receptors within the foetal brain (Eyles et al. 2011) highlights the critical importance of vitamin D for optimal neurodevelopment and subsequent function. Prominent focus has been placed on this in the context of epidemiological associations between early life vitamin D deficiency and increased incidence of offspring schizophrenia (McGrath et al. 2004, 2010). 
In animal models of early life vitamin D deficiency, there is substantial overlap with changes in brain systems commonly associated with schizophrenia (Eyles et al. 2009), including striking changes in lateral ventricle size (Eyles et al. 2003, Hawes et al. 2015) and marked changes in the dopamine (DA) system (Kesby et al. 2006, 2009, Cui et al. 2010, 2013). However, the generic role that vitamin $\mathrm{D}$ has in brain development and function likely means that vitamin D deficiency associates with many other neuropsychiatric outcomes.

We have recently shown that vitamin D deficiency in mice increases placental glucocorticoid transfer and increases fetal brain glucocorticoid exposure, which is known to alter adult behavioural outcomes (Holmes \& Seckl 2006, Wyrwoll \& Holmes 2012). A further key determinant of adult behaviour is the quality of maternal care experienced in early life. Pregnancy and lactation necessitate marked changes in the maternal brain to facilitate offspring care (Bridges 2016). In rats, the time spent licking and grooming pups has a potent effect on epigenetic modifications and neuroendocrinology in the offspring brain, which result in altered adult behaviours (Weaver et al. 2004). Whether vitamin D levels contribute to these maternal behaviours is unclear. Furthermore, vitamin $\mathrm{D}$ deficiency also reduces forkhead box protein $\mathrm{P} 2$ (FOXP2)-immunoreactive cells in the mouse foetal cortex (Hawes et al. 2015). FOXP2 is known to be important in human speech and language (Fisher \& Scharff 2009) but whether the changes seen in FOXP2 in rodent models of vitamin $\mathrm{D}$ deficiency associate with altered vocalisations is unknown. Thus, vitamin D likely has key roles to play in many pathways that are integral for offspring neurodevelopment and brain function.

There is emerging evidence for associations of vitamin D deficiency with autism spectrum disorder (ASD) (Fernell et al. 2010, 2015, Vinkhuyzen et al. 2018), which is characterised by qualitative impairments in social interaction and communication and a restricted range of activities and interests. Reduced vitamin D exposure during early life is also associated with individual behaviours that comprise the ASD phenotype, such as language difficulties (Whitehouse et al. 2012). Furthermore, vitamin D supplementation during pregnancy in a mouse model of maternal immune activation prevents the development of autism-like behaviours in the adult offspring (Vuillermot et al. 2017). However, the purported link between early life vitamin D status and ASD is yet to be comprehensively investigated in experimental models.

Here, we utilise a Sprague-Dawley rat model of vitamin $\mathrm{D}$ deficiency during gestation and lactation to assess maternal care, offspring neurodevelopmental markers, ultrasonic vocalisations and adult behavioural outcomes including social, cognitive and affective-like behaviours. Magnetic resonance imaging (MRI) scans were conducted to assess offspring brain morphology. Plasma corticoisterone levels and gene expression associated with language, dopamine and glucocorticoid exposure were characterised. Our data indicate that early life vitamin D deficiency in rats elicits changes in maternal care, while offspring exhibit altered ultrasonic vocalisations, social interaction and cognition, with associated changes in gross brain structure, FOXP2 immunostaining and dopaminergic gene expression in neural tissue.

\section{Materials and methods}

\section{Animals}

Sprague-Dawley rats were supplied by the Animal Resources Centre (ARC, Murdoch, Western Australia). All animal procedures were conducted with approval of the Animal Ethics Committee of the University of Western Australia (RA/3/100/1333). Rats were maintained in environmentally controlled rooms with a 12:12 light/ darkness cycle (lights on at 07:00h) and food and water were supplied ad libitum. Five-week-old female SpragueDawley rats were provided with vitamin D-deficient (0IU/kg, $n=15)$ or vitamin D control (2195 IU/kg, $n=15)$ diets (Specialty Feeds, Glen Forrest, Western Australia) for a minimum of five weeks before mating. Deficient diets were supplemented with $25 \mathrm{~g} / \mathrm{kg}$ calcium, and caloric content was controlled to ensure similar energy intake (deficient: $15.3 \mathrm{MJ} / \mathrm{kg}$; control: $15.8 \mathrm{MJ} / \mathrm{kg}$ ). Female rats were mated randomly with Sprague-Dawley males consuming the control diet and then housed separately. Litter size was standardised to five males at postnatal day (PND) 1. At weaning, all offspring were fed the control diet and housed with littermates with a minimum of two animals per cage to prevent social isolation effects.

\section{Maternal care}

Maternal behaviour assessment was conducted as detailed in Capone et al. (2005). Briefly, from PND3-8, maternal care was recorded using a Webcam (Logitech C270) for $1 \mathrm{~h}$ using iSpy software (www.ispyconnect.com) at 06:00, 10:00, 13:00, 17:00 and 20:00 h. Behaviour of the dam (licking pups, nursing, self-grooming, drinking, eating, digging, rearing, walking and resting away from nest) was 
scored for 20s every four minutes of the recording (AVI Explorer, (c) 2015, NJ Yates). The observer was blind to maternal diet. At PND7 after the 06:00-h recording, pup retrieval testing was conducted. The dam and pups were placed in separate cages (with the pups incubated at $32^{\circ} \mathrm{C}$ ) for $15 \mathrm{~min}$. The dam was then removed from her cage, one pup was placed in each cage corner and the dam returned, with time taken to retrieve pups timed. If after $10 \mathrm{~min}$ all pups had not been retrieved, testing stopped and the pups returned.

\section{Assessment of neurodevelopment markers}

To assess markers of neurodevelopment in early postnatal life, negative geotaxis, righting reflex and timing of eye opening were assessed from PND3 to PND14 as previously detailed (Holmes et al. 2006).

\section{Ultrasonic vocalisations}

At PND12, ultrasonic vocalisations of the pups were assessed. A pup from each litter was removed from the dam and placed within an aerated clean Perspex box situated in a sound proof room. The Perspex box contained a warming pad to maintain pup body temperature. Ultrasonic vocalisations (ultrasonic vocalisation) were recorded for $5 \mathrm{~min}$. The pup was then returned to the litter for $5 \mathrm{~min}$ before a subsequent $5 \mathrm{~min}$ re-isolation period to record vocalisations. Ultrasonic vocalisations were acquired using a bat detector (Batbox Baton, Batbox Ltd.) linked to a laptop and recorded using Audacity (C 2016 Audacity Team). After the second recording, pups were killed and tissues were collected for subsequent analyses. Sound recordings were analysed using custommade software (Sound Spectrum Analyser, (C) 2015, NJ Yates) for sound intensity, frequency and duration.

\section{Adult offspring behavioural assessments}

Adult behavioural testing was performed during the light period between 07:00 and 14:00 h at four months of age. When appropriate, behavioural tests were recorded using a Webcam (Logitech C270) using iSpy software. Analysis of the videos was performed offline using the Anymaze tracking system (Stoelting, IL, USA). All animals were habituated to the testing room for a minimum of $30 \mathrm{~min}$ prior to each test. Where applicable, testing setups were counterbalanced. Between tests, all apparatus were thoroughly cleaned with $70 \%$ ethanol to eliminate odour cues. All assessments were conducted blind to treatment.
The assessments tested motor function (using a rotarod and open field), social behaviours (social interaction test), anxiety-like behaviours (open field and elevated plus maze), grooming behaviour, learning and memory (object recognition and object-in-place) and anhedonia (sucrose preference test). Specific details of these tests can be found in the Supplementary Materials and methods (see section on supplementary data given at the end of this article).

\section{MRI scans}

At the completion of behavioural assessments, offspring were scanned using MRI to assess brain morphology. The rats were scanned under general anaesthesia ( $1.5 \%$ isoflurane in $100 \%$ medical oxygen, supplied at $\sim 1.5 \mathrm{~L} / \mathrm{min}$ ) using a Bruker BioSpec 94/30 US/R magnet $\left(B_{0}=9.4 \mathrm{~T}\right)$, Avance III HD Console, BGA-12SHP gradients, ParaVision 6.0 software, $86 \mathrm{~mm} \mathrm{H-1}$ quadrature transmitonly volume coil and a rat brain $\mathrm{H}-1$ quadrature surface receive coil (Bruker BioSpin GmbH, Ettlingen, Germany). MRI slices were examined for each animal using ITK-SNAP software. Further information on the scanning parameters and volume analysis is included in the Supplementary Materials and methods.

\section{Tissue and blood collection}

Offspring tissue collections were conducted at PND1, PND12 and four months of age. One male offspring from each litter was decapitated at PND1, the brains dissected from the skull and snap-frozen whole for subsequent gene analysis. At PND12, the pups assessed for ultrasonic vocalisations were decapitated and whole heads were fixed for later histological analysis. Blood was collected at weaning from the dams and one offspring from each litter to assess maternal and offspring vitamin D status. Blood samples were prepared and assessed for vitamin $\mathrm{D}$ status and corticosterone using LC/MS/MS as previously described (Clarke et al. 2013, Wharfe et al. 2016). At approximately four months of age, after the behavioural investigations and MRI scans, offspring were anaesthetised (Isoflurane/nitrous oxide) for blood and tissue collections. Brains were dissected into cortex, hippocampus, mesencephalon and cerebellum and snap-frozen for subsequent gene expression analysis.

\section{Immunohistochemistry}

Briefly, whole fixed PND12 brains were transferred to $0.1 \mathrm{M}$ sodium phosphate buffer (PBS), 30\% sucrose for 
five days prior to sectioning on a cryostat. A set of brain sections ( $40 \mu \mathrm{m}$ thick, $200 \mu \mathrm{m}$ apart) were immunostained and quantified for FOXP2 (1:200; N-16, sc-21069, Santa Cruz Biotechnology) or tyrosine hydroxylase (TH, 1:2000; NCL-TH, Novocastra, Leica Microsystems) with relevant primary and secondary antibody controls as previously described (Hawes et al. 2015).

\section{Real-time qRT-PCR}

Total RNA was isolated from tissue samples and transcribed to cDNA as previously described (Tesic et al. 2015). Analyses of rat mRNA expression levels of genes encoding for dopamine receptor D1 (Drd1), dopamine receptor D2 (Drd2), glutamic acid decarboxylase (Gad1), N-methyl D-aspartate receptor subtype 2B (Grin $2 b)$, glucocorticoid receptor $(\mathrm{Nr} 3 \mathrm{c} 2), 11 \beta$-hydroxysteroid dehydrogenase type 1 (Hsd11b1), 11ß-hydroxysteroid dehydrogenase type 2 (Hsd11b2), glucocorticoid-induced leucine zipper (Tsc22d3), and the reference genes Ppia, Sdha and Tbp were performed by real-time PCR on the Rotorgene 6000 system (Corbett Research, Sydney, Australia). Primer pairs for all genes (Table 1) were purchased as QuantiTech primers with the exception of Ppia, Sdha and Tbp, which were designed using Primer-BLAST (http://www.ncbi.nlm. nih.gov). Primer pairs were designed to span introns to prevent amplification of product from genomic DNA. Melt-curve analysis showed a single PCR product for each gene, which was confirmed by gel electrophoresis and DNA sequencing. Standard curves were generated with 10-fold serial dilutions of gel extracted (QIAEX II; Qiagen) PCR products and relative gene expression were analysed using the Rotorgene 6000 software. All samples were run in duplicate and normalised against Ppia, Sdha and Tbp using the GeNorm algorithm (Groves et al. 2013).

\section{Statistical analysis}

Statistical analyses were performed using $\mathrm{R}$ (version 3.2.2) and R Studio (version 0.99.482) and/or GraphPad Prism (version 7.03). All data were assessed for violations of normality and homogeneity of variance. In general $t$-tests were used to assess differences between groups, with the exception of ultrasonic vocalisation total call number (Kurskal-Wallis ranked-sum test, violations of equal variance and normality), ultrasonic call frequencies (two-way ANOVA) and open field testing (repeatedmeasures two-way ANOVA) due to multifactorial study design. Maternal care from PND3-8 was analysed using
Table 1 Qiagen name, primer sequences and melting temperature $\left(T_{m}\right)$ for analysis and reference genes.

\begin{tabular}{|c|c|c|}
\hline Gene & Qiagen name or primer sequence & $\begin{array}{l}\text { Catalogue no. } \\
\text { or } T_{m}\left({ }^{\circ} \mathrm{C}\right)\end{array}$ \\
\hline Drd1 & DRD1 & QT00386631 \\
\hline Drd2 & DRD2 & QT01081990 \\
\hline Gad1 & GAD1 & QT00194600 \\
\hline Grin $2 b$ & GRIN2B-(NMDA subunit) & QT00184793 \\
\hline $\mathrm{Nr} 3 \mathrm{c} 2$ & $\mathrm{Nr3c}$ & QT00195251 \\
\hline Hsd11b1 & HSD11-B1 & QT00107303 \\
\hline Hsd11b2 & HSD11-B2 & QT00252609 \\
\hline$T s c 22 d 3$ & TSC22D3 & QT00404075 \\
\hline \multirow[t]{2}{*}{ Sdha } & F, 5'-TGGGGCGACTCGTGGCTTTC-3' & 60 \\
\hline & $\mathrm{R}, 5^{\prime}$-CCCCGCCTGCACCTACAACC- $3^{\prime}$ & 60 \\
\hline \multirow[t]{2}{*}{$T b p$} & F, 5'-GGCTGCTCGTTTTTG-3' & 62 \\
\hline & R, 5'-TGGGGAGGCCAAGCCCTGAG-3' & 62 \\
\hline \multirow[t]{2}{*}{ Ppia } & F, 5'-AGCATACAGGTCCTGGCATC-3' & 60 \\
\hline & R, 5'-TTCACCTTCCCAAAGACCAC-3' & 60 \\
\hline
\end{tabular}

Drd1, dopamine receptor D1; Drd2, dopamine receptor D2; F, forward; Gad1, glutamic acid decarboxylase; Grin2b, $N$-methyl D-aspartate receptor subtype 2B; Hsd11b1, 11 $\beta$-hydroxysteroid dehydrogenase type 1;

Hsd11b2, 11 -hydroxysteroid dehydrogenase type 2; Nr3c2, glucocorticoid receptor; Ppia, peptidylprolyl isomerase A; R, reverse; Sdha, succinate dehydrogenase complex, subunit A; Tbp, TATA box binding protein; $T s c 22 d 3$, glucocorticoid-induced leucine zipper.

two-way ANOVA as occasional time points were missing, which prevented repeated-measures analysis.

\section{Results}

Vitamin D deficiency alters maternal care and offspring ultrasonic vocalisations but not neurodevelopmental markers

Assessment of maternal care from PND3 to 8 revealed that vitamin $\mathrm{D}$ deficiency caused variation in the percentage of total time spent licking and grooming pups (Fig. 1A, $F(1,105)=7.544, P<0.01$, two-way ANOVA), but there was no effect of day or an interaction between diet and postnatal day. When comparing the percentage of total time spent licking and grooming over the entire duration of PND3-8, vitamin D-deficient dams spent 27\% less time grooming their pups in comparison to controls (Fig. 1B, $t(21)=2.85, P<0.01, t$-test). Pup retrieval parameters did not significantly alter between control and vitamin D-deficient dams (Fig. 1C, $t(20)=1.614, P=0.1223$, $t$-test).

At PND12, ultrasonic call rates were increased in vitamin D-deficient pups during the first period of maternal separation in comparison to controls (KruskalWallis rank sum test, $\chi^{2}=6.89, d f=1, P<0.01$; Fig. 2A) although a difference between controls and vitamin D-deficient pups was not apparent in the second separation 


\begin{tabular}{l|l|l|l|l|}
$\begin{array}{l}\text { Journal of } \\
\text { Endocrinology }\end{array}$ & N J Yates et al. & $\begin{array}{l}\text { Vitamin D, maternal care and } \\
\text { adult behaviour }\end{array}$ & $\mathbf{2 3 7 : 2}$ & $\mathbf{7 7}$ \\
\hline
\end{tabular}
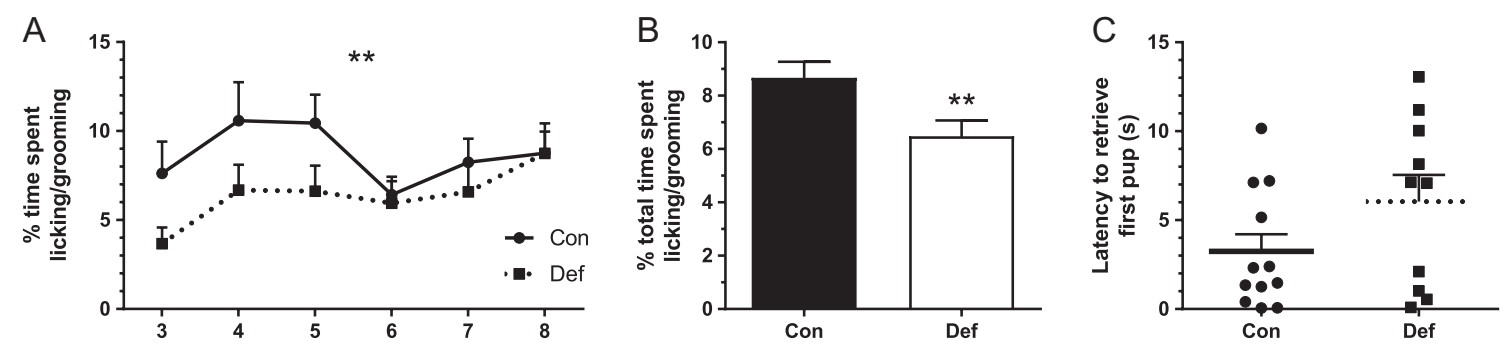

Figure 1

Vitamin D levels altered maternal care parameters in the first postnatal week. (A) Maternal vitamin D deficiency had a significant effect on the amount of time the dam spent licking and grooming her pups, but there was no effect of day or interaction between diet and day. (B) Combining all the data points from PND3 to 8 demonstrates the extent to which vitamin D deficiency decreased total licking and grooming from PND3 to 8. (C) At PND7 there were no differences in the latency for control or vitamin D-deficient dams to retrieve their pups during the pup retrieval test. Bars indicate mean +S.E.M. $(n=12$ control dams and 10 vitamin D-deficient dams). Significant differences; two-way ANOVA or $t$-test, $* P<0.05, * * P<0.01$.

(Kruskal-Wallis rank sum test, $\chi^{2}=1.085, d f=1, P>0.05$; Fig. 2A). The lack of difference in the second separation between the two experimental groups is due to a $170 \%$ increase in call rates from the control pups between the first and second maternal separations (Kruskal-Wallis rank sum test, $\left.\chi^{2}=3.98, d f=1, P<0.05\right)$, which was not evident in the vitamin D-deficient pups (5\% increase, Kruskal-Wallis rank sum test, $\chi^{2}=0.05, d f=1, P>0.05$ ). The distribution of call peak frequencies was unchanged in both experimental groups in the first and second recording (two-way ANOVA; Fig. 2B and C). Due to the directional and easily attenuated nature of ultrasonic vocalisations, the intensity of calls was not suitable for analysis.

We then examined whether changes in ultrasonic vocalisations were accompanied by alteration in neural tissue expression of FOXP2, a gene in part implicated in speech and language development (Fisher \& Scharff 2009). FOXP2 protein immunostaining was reduced by $43 \%$ in the cortex of vitamin D-deficient male brains at PND12 compared to controls $(P<0.05$; Fig. $3 \mathrm{~A}, \mathrm{~B}$, $\mathrm{C}$ and D). No significant differences in FOXP2 were distinguished in the caudate putamen, amygdala, post thalamic nucleus or post thalamic group (all $P>0.05$, data not shown). We also investigated TH levels at PND12, but no differences were detected in TH immunostaining in either the substantia nigra pars compacta or ventral tegmental area of control and vitamin D-deficient brains (all $P>0.05$; Fig. 3E, F and G).

Maternal vitamin D diet allocation had no effect on routine measures of offspring neurodevelopment (timing of eye opening, negative geotaxis, righting reflex) or other gross parameters such as gestation length, litter size, offspring sex ratio or offspring weight (Table 2). At weaning, maternal and offspring serum $25(\mathrm{OH})$ D3 and 3-epi-25(OH)D3 concentrations reflected diet consumption (Table 2).

\section{Early life vitamin D deficiency impairs adult social-like behaviours, cognition and grooming behaviours but not affective behaviours}

In the social interaction test, adult offspring exposed to vitamin D deficiency in early life spent $22 \%$ less time in the chamber containing the social cue compared to
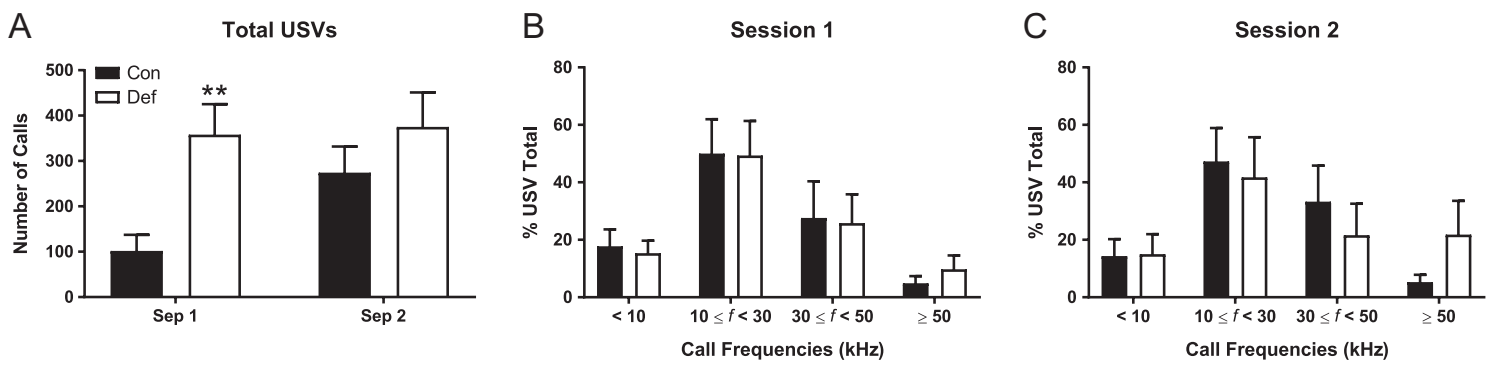

Figure 2

Ultrasonic vocalisations (USV) of PND12 pups upon 5-min repeated maternal separation. (A) Ultrasonic vocalisation total call number was markedly increased in vitamin D-deficient pups for the first (Sep 1), but not the second (Sep 2) maternal separation period. For each separation period, the calls were also classified based upon the peak frequency of the call ( $f$ ), shown in panels (B) and (C). However, these did not differ. Bars indicate mean + S.E.M. ( $n=8$ for both control and vitamin D-deficient groups). Significant differences: Kurskal-Wallis, $* * P<0.01$. 

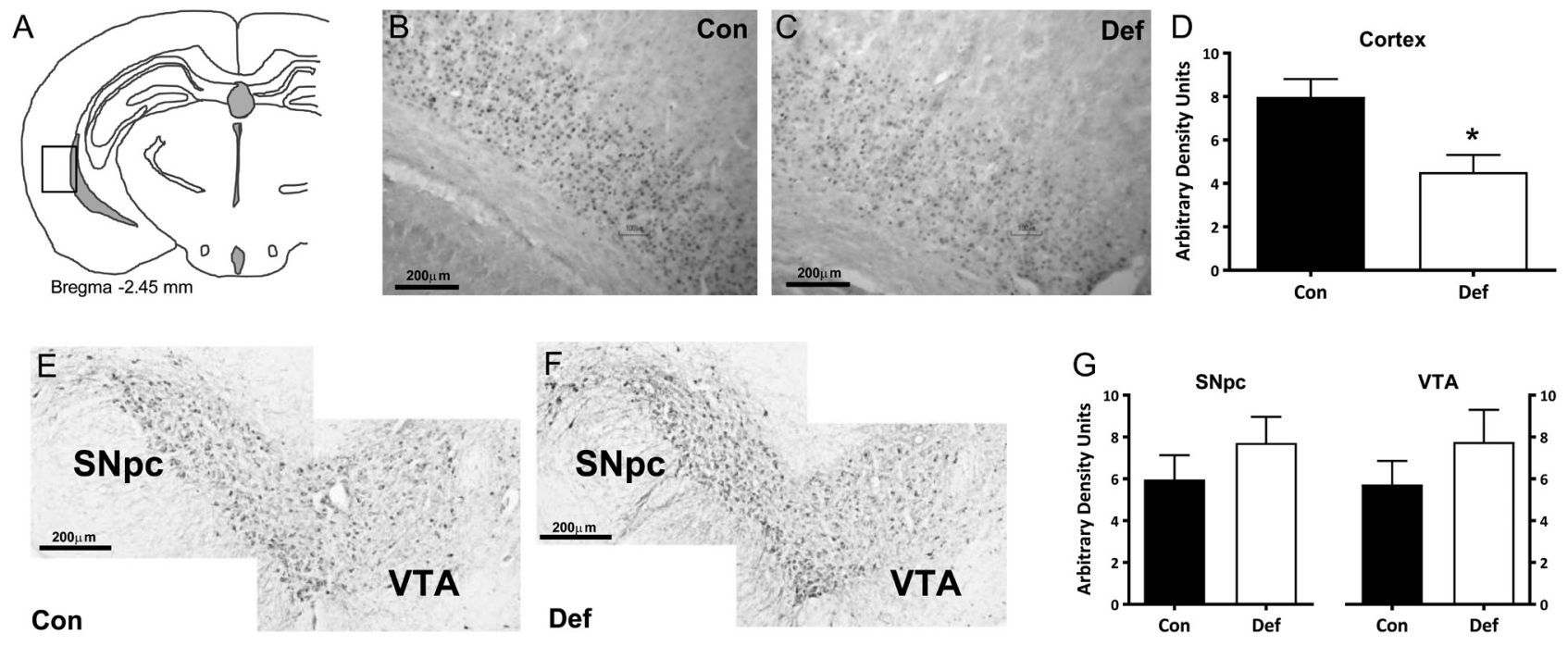

Figure 3

FOXP2, but not TH, immunolabelling was decreased in vitamin D-deficient pups in comparison to control at PND12. FOXP2 immunolabelling and analysis is shown in panels (A, B, C and D). (A) Coronal schematic representation of region of interest for immunohistochemical labelling of FOXP2 in the cortex of PND12 animals. The box represents the region shown in example (B) control and (C) vitamin D-deficient images of FOXP2 immunolabelling in the cortex and was used for (D) semi-quantitative immunointensity analysis. Tyrosine hydroxylase (TH) immunolabelling and analysis is shown in panels $(E, F$ and G). Example substantia nigra pars compacta (SNpc) and ventral tegmental area (VTA) immunolabelling in (E) control and (F) vitamin D-deficient animals. (G) Semi-quantitative analysis revealed no differences in TH immunointensity. Bars show mean + S.E.M., $n=6-8$ per diet group. Significant differences: $t$-test, ${ }^{*} P<0.05$.

control offspring $(P<0.05$, Student's $t$-test; Fig. $4 \mathrm{~A})$. This lack of specific interest in the social cue was further demonstrated by the vitamin D-deficient offspring spending $26 \%$ less time directly around the social cue cage in comparison to controls $(P<0.05$, Student's $t$-test; Fig. 4B). Overall exploration of the maze (as measured by total distance travelled in the maze) did not differ between control or vitamin D-deficient offspring $(35.65 \pm 3.40 \mathrm{~m}$ and $35.00 \pm 3.00 \mathrm{~m}$ respectively).

In the object recognition test, control and early life vitamin D-deficient offspring exhibited similar discrimination ratios for novel object recognition $(1.77 \pm 0.30$ and $1.63 \pm 0.32$, respectively; Fig. 4 C). However, the more complex object-in-place task revealed cognitive differences. Offspring that had been exposed to vitamin D deficiency in early life were unable to discriminate between the objects that had swapped positions and those that had remained in the same position as in the sample phase. In comparison, control littermates showed discrimination by investigating the moved objects longer than the objects that were in their original position $(P<0.05$, Fig. $4 \mathrm{D})$.

Sucrose preference testing indicated that there was no indication of anhedonia with control and vitamin D-deficient offspring showing equal preference for sucrose (Fig. 4E). In the open field testing, on the standard testing days or days with restraint stress, there were no differences between the groups effects or interactions with testing day on total distance travelled (Fig. 4F), ratio of time spent in the centre compared to periphery (Fig. 4G) or any other outcome measured (all $P>0.05$, repeated-measures 2-way ANOVA). In rotarod assessments, offspring showed no difference in motor coordination (time to fall in control offspring: $120 \pm 58 \mathrm{~s}$; vitamin D deficient: $110 \pm 22 \mathrm{~s}$ ). Assessment for anxiety-like behaviours using the elevated plus maze was unsuccessful on the test day as neither group explored the open arm extensively. The reason for this is uncertain; experimental parameters had been earlier optimised and tested to ensure appropriate elevated plus maze exploration. However, grooming behaviours were scored during this test and suggest increased restricted and repetitive behaviour in vitamin D-deficient offspring, which groomed for longer, but with similar grooming frequency over the five-minute test period (grooming duration: Kruskal-Wallis, $P<0.05$, Fig. 4H; grooming frequency: Kruskal-Wallis, $P>0.05$, Fig. 3I).

\section{Adult lateral ventricle volume and neural gene expression are altered by early life vitamin $D$ deficiency}

MRI scans revealed that vitamin D deficiency in early life enlarged lateral ventricle size markedly by $140 \%$ at four months of age in comparison to controls $(P<0.05$; Fig. 5). In contrast, early life vitamin D status did not alter 
Table 2 General pregnancy characteristics, vitamin D serum concentrations (25(OH)D3 and 3-epi-25(OH)D3) in dams and offspring at time of weaning, postnatal weight gain, neurodevelopmental markers and plasma corticosterone concentrations of control and vitamin D-deficient offspring.

\begin{tabular}{|c|c|c|}
\hline & Control & $\begin{array}{l}\text { Vitamin D } \\
\text { deficient }\end{array}$ \\
\hline \multicolumn{3}{|l|}{ Pregnancy characteristics } \\
\hline Gestation length (days) & $22.5 \pm 0.2$ & $22.1 \pm 0.1$ \\
\hline Litter size & $12.4 \pm 1.1$ & $11.1 \pm 1.0$ \\
\hline Gender ratio (M:F) & $1.2 \pm 0.2$ & $1.2 \pm 0.2$ \\
\hline \multicolumn{3}{|l|}{ Postnatal weight (g) } \\
\hline PND1 & $7.5 \pm 0.4$ & $7.4 \pm 0.3$ \\
\hline PND12 & $33.8 \pm 2.2$ & $37.1 \pm 0.9$ \\
\hline PND21 & $70.3 \pm 2.9$ & $72.7 \pm 2.8$ \\
\hline PNW16 & $510.3 \pm 16.6$ & $518.4 \pm 20.5$ \\
\hline \multicolumn{3}{|l|}{ Neurodevelopment } \\
\hline Eye opening (PND) & $13.8 \pm 0.2$ & $14.4 \pm 0.2$ \\
\hline Negative geotaxis (s) & $21.0 \pm 2.8$ & $20.7 \pm 2.6$ \\
\hline Righting reflex (s) & $2.2 \pm 0.4$ & $1.8 \pm 0.3$ \\
\hline \multicolumn{3}{|c|}{ Vitamin D serum concentration ( $\mathrm{nmol} / \mathrm{L})$} \\
\hline \multicolumn{3}{|l|}{ Dams } \\
\hline 25(OH)D3 & $35.42 \pm 1.69$ & $3.33 \pm 0.62 * * *$ \\
\hline 3-Epi-25(OH)D3 & $21.46 \pm 6.53$ & $0.82 \pm 0.23 * * *$ \\
\hline \multicolumn{3}{|l|}{ Offspring } \\
\hline 25(OH)D3 & $23.85 \pm 1.89$ & $1.63 \pm 0.13 * * *$ \\
\hline 3-Epi-25(OH)D3 & $20.04 \pm 6.65$ & $0.39 \pm 0.24 * * *$ \\
\hline
\end{tabular}

Maternal vitamin D status had no effect on gestation length, litter size, or offspring gender ratios. Furthermore, there was no effect of early life vitamin $\mathrm{D}$ deficiency on offspring weight or measures of neurodevelopment at any time point measured (PND1, PND12, PND21 or PNW16). At weaning, maternal and offspring serum 25(OH)D3 and 3-epi-25(OH)D3 concentrations reflected diet consumption with both dams and offspring exhibiting a marked reduction in 25(OH)D3 and 3-epi-25(OH)D3 if consuming a vitamin D-deficient diet. Vitamin D deficiency did not alter offspring plasma corticosterone at any time point. Values are the mean \pm s.E.m. $* * * P<0.001 ;$ t $t$ test.

PND, postnatal day; PNW, postnatal week.

cerebellum, hippocampus, corpus callosum or total brain volume (all $P>0.05$ )

Changes were observed at PND1 in genes associated with dopamine signalling and GABA synthesis. The expression of Gad1, which encodes for a GABA synthesis enzyme, showed a $48 \%$ decrease in the whole brains of vitamin D-deficient animals $(P<0.05$; Fig. 5D), while the expression of dopamine receptor Drd2 was decreased by $42 \%$ in the vitamin D-deficient pups in comparison to controls $(P<0.05$; Fig. 5E). At four months of age, gene expression was analysed in dissected brain regions, with only discrete changes observed. Thus, of the genes analysed, Drd 2 was decreased by $44 \%$ in the cerebellum of offspring exposed to vitamin D deficiency in early life in comparison to control $(P<0.05$; Fig. $5 \mathrm{~F})$ and Grin $2 b$ expression was decreased by $48 \%$ in the mescencephalon of vitamin D-deficient offspring $(P<0.01$; Fig. 5G).
Glucocorticoid-related genes are only altered at PND1 while offspring plasma corticosterone levels did not vary

Expression of genes involved in glucocorticoid-related pathways was also assessed and changes were only evident at PND1. Thus, whole-brain $H s d 11 b 2$, which converts active glucocorticoids to their inactive form, was decreased by over $50 \%$ in vitamin D-deficient offspring in comparison to control $(P<0.05$; Fig. 6A). The glucocorticoid receptor, $\mathrm{Nr} 3 \mathrm{c} 2$, was also decreased by vitamin D deficiency (34\%, $P<0.05$; Fig. 6B) while $T s c 22 d 3$ expression, an indication of glucocorticoid receptor activation, was increased by over 2.5-fold ( $P<0.05$; Fig. 6C). Offspring corticosterone concentrations did not vary at PND1, weaning or four months of age (Fig. 6D).

\section{Discussion}

Early life vitamin D deficiency in male rats resulted in a phenotype characterised by atypical pup ultrasonic vocalisations and impairments in adult social, memory and learning behaviours as well as increased grooming. This was accompanied by a marked increase in lateral ventricle volume, altered neural proteins implicated in language development and differential neural expression of genes involved in neurotransmitter signalling and increased early life glucocorticoid exposure. Furthermore, the quality of maternal care was decreased in dams consuming a vitamin D-deficient diet. These data demonstrate that vitamin D deficiency in early life influence multiple pathways that are critical for optimal neural development and adult brain function. Of particular interest is that aspects of the behavioural phenotype are suggestive of features of ASD, including communication differences, lack of interest in social interaction, restricted and repetitive behaviour and changes in brain development.

Variation in maternal care has a profound influence on offspring neurodevelopment and neuropsychiatry (Curley \& Champagne 2016). Therefore, the reduction in maternal licking and grooming in dams consuming a vitamin D-deficient diet is a likely important contributor to the adult offspring behavioural phenotype that results from early life vitamin D deficiency. Extensive work has highlighted the crucial role of maternal care in epigenetic modifications in the offspring brain and the optimal development of neural circuitry, including neuroendocrine systems such as the hypothalamicpituitary-adrenal (HPA) axis and dopaminergic pathways 
A

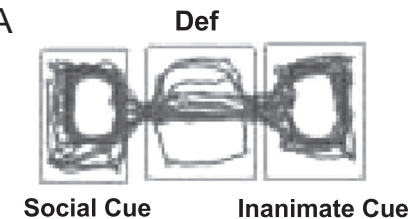

ii

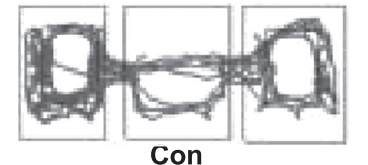

B

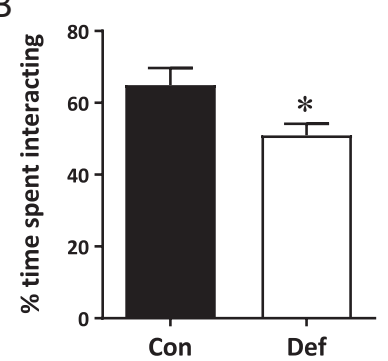

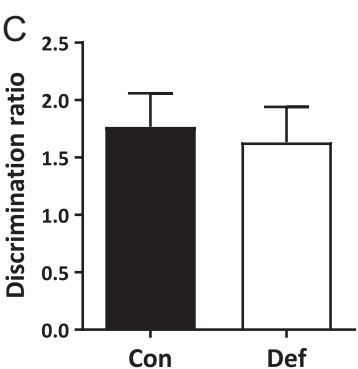
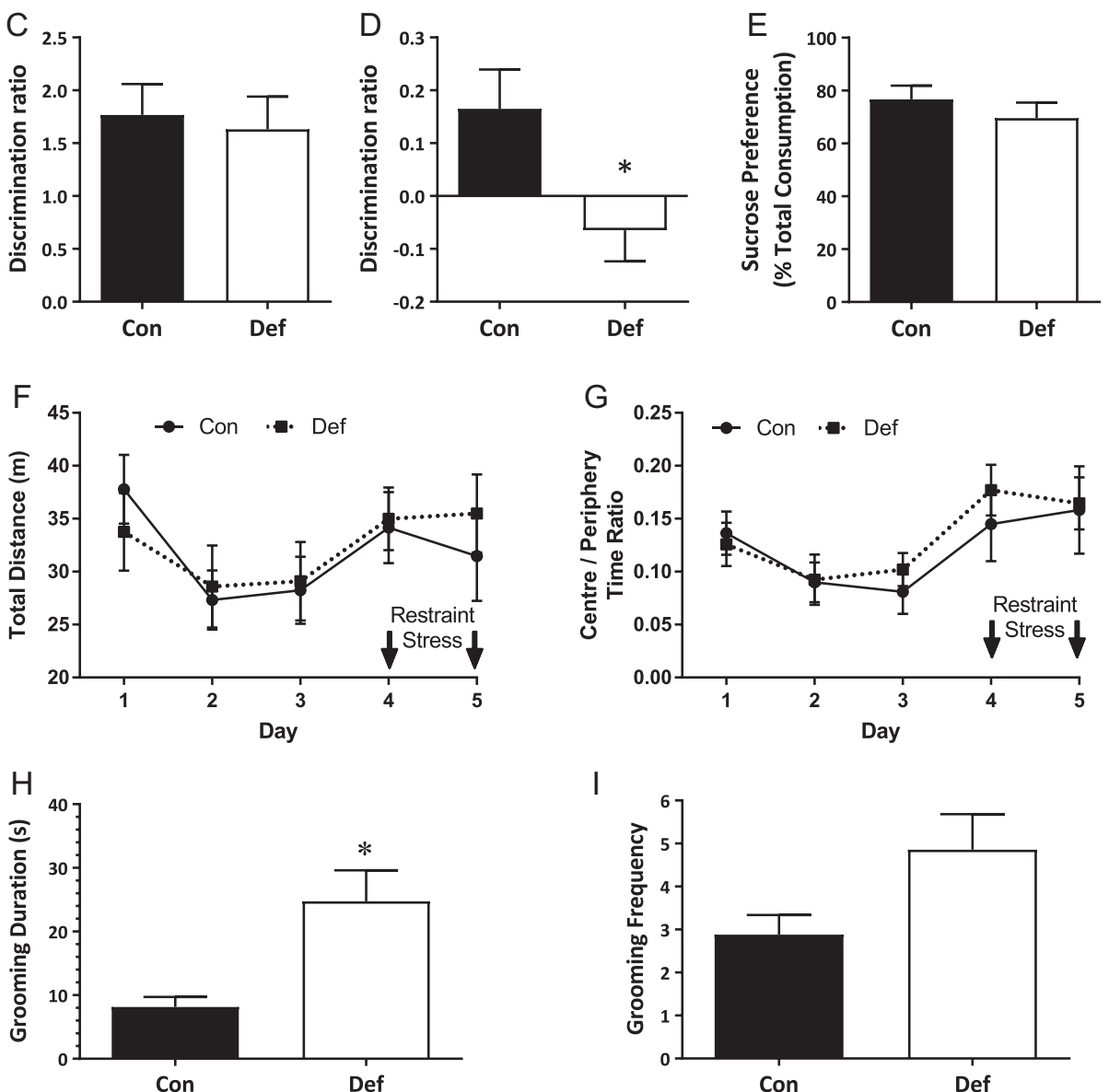

I

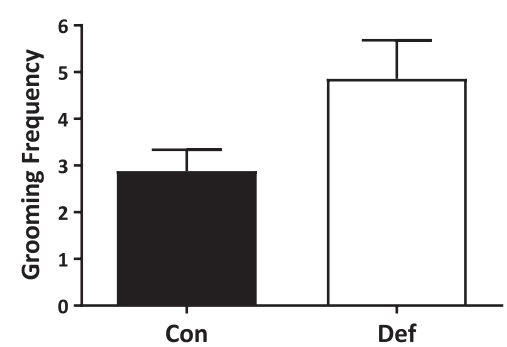

Figure 4

Adult social and cognitive behaviours were decreased animals exposed to early life vitamin D deficiency in comparison to control. Social interaction test: (A) example exploration traces percentage of time spent in the social cue chamber containing the novel rat for (i) vitamin D-deficient offspring and (ii) control offspring. Social preference was quantified by (B) percentage of time socially interacting in the social cue chamber. Cognitive outcomes: (C) novel object recognition discrimination ratio after $1 \mathrm{~h}$ separation, and (D) object-in-place discrimination ratio. Sucrose preference test assessment of anhedonia revealed no differences $(E)$ as assessed by preference for sucrose solution over water. Open field test outcomes were unaltered between the groups during standard testing days (days 1-3) and following restraint stress (days 4 and 5), (F) total distance travelled and G) centre/periphery exploration time ratio. While exploration of the elevated plus maze could not be assessed, grooming behaviour was scored. Early life vitamin $\mathrm{D}$ deficiency increased total grooming duration $(\mathrm{H})$ but not grooming frequency (I). Bars represent mean +S.E.M., $n=10-15$ per diet group. Significant differences: $t$-test or KruskalWallis, $* P<0.05$.

(Meaney et al. 1996, Weaver et al. 2004, Pena \& Champagne 2015). Indeed, we and others find consistent evidence of early life vitamin D deficiency altering dopaminergic-related pathways in the adult brain (Kesby et al. 2006, 2009, Cui et al. 2010, 2013, Hawes et al. 2015). Adult HPA axis parameters do not differ our model, although intracellular changes have not yet been properly characterised. Therefore, the degree to which the altered maternal behaviour in our current study contributes to the adult offspring phenotype is unclear and further cross-fostering studies are required to elucidate this. Furthermore, our experimental design meant that litter size was reduced to six male pups only, which is not standard in maternal behavioural assessments. This may have skewed maternal behaviours and further work is required to clarify this point.

The brain-specific mechanisms underlying the reduction in licking and grooming behaviours in vitamin D-deficient mothers in our model are uncertain. Given that dopamine is important in the establishment of maternal behaviours (Numan 2007), this could be a key area for further investigation. Indeed, the impact of vitamin $\mathrm{D}$ deficiency on dopaminergic pathways has been extensively characterised (Kesby et al. 2006, 2009, Cui et al. 2010, 2013), although not in the context of maternal behaviours. Previous studies have reported an association between reduced maternal vitamin D levels during pregnancy and perinatal depressive symptoms, 


\begin{tabular}{|l|l|l||c|c|}
$\begin{array}{l}\text { Journal of } \\
\text { Endocrinology }\end{array}$ & N J Yates et al. & $\begin{array}{l}\text { Vitamin D, maternal care and } \\
\text { adult behaviour }\end{array}$ & $\mathbf{2 3 7 : 2}$ & $\mathbf{8 1}$ \\
\hline
\end{tabular}
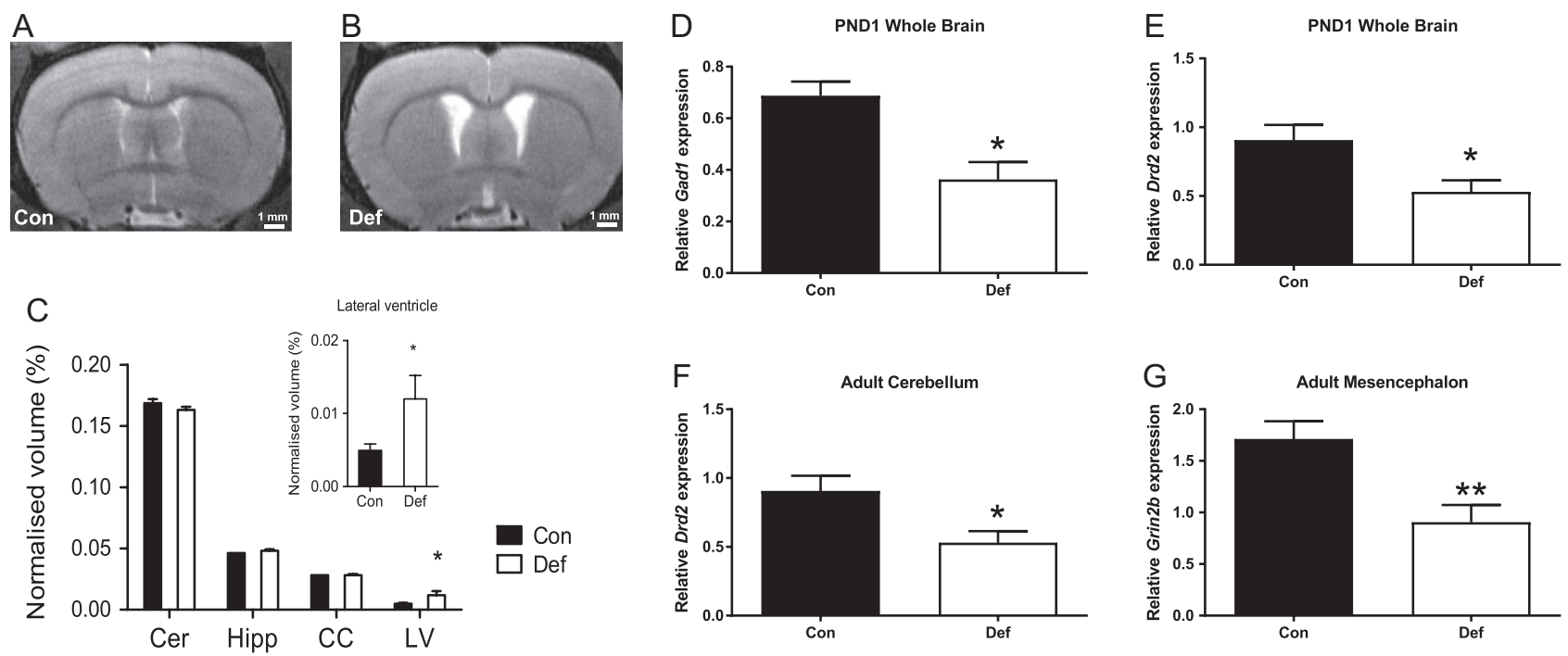

Figure 5

MRI volumetric analysis of brains from PNW16 control and vitamin D-deficient animals, and relative changes in gene expression. Example images illustrating the marked differences in lateral ventricle volumes of (A) control and (B) vitamin D-deficient animals at a comparable section level of the brain. (C) Volume of brain regions of the cerebellum (Cer), hippocampus (Hipp), corpus callosum (CC) and lateral ventricles (LV) normalised to total brain volume. Early life vitamin D deficiency caused a downregulation in some genes involved in dopaminergic pathways. Relative gene expression to house-keeping genes for whole brain on postnatal day 1 (PND1) for: (D) GABA synthesis enzyme, Gad1; (E) dopamine receptor type 2, Drd2. Adult (4 months old) brain regional gene expression for (F) dopamine receptor type 2, Drd2, in the cerebrellum; and (G) NMDA receptor subunit, Grin2b, in the mesencephalon. Bars show mean +s.E.M., $n=8$ for both control and vitamin D-deficient groups. Significant differences: $t$-test, ${ }^{*} P<0.05, * * P<0.01$.

which may indicate that dopamine-related pathways underlie abnormal maternal behavioural outcomes in vitamin D-deficient pregnancies (Robinson et al. 2014, Vaziri et al. 2016, Williams et al. 2016).

Our current study is the first to identify increased ultrasonic vocalisation call rates during forced isolation in a rat model of vitamin D deficiency. This increased call rate was marked in the first maternal separation but not the second, likely due to the maximum threshold of call rates already having being reached. Another possibility may be that vitamin D-deficient pups have impaired auditory detection and are unable to monitor their vocalisations, although more research is required to clarify this possibility. Interestingly, removal of vitamin D receptor in zebra fish elicits impaired inner ear development (Kwon 2016). Our observations differ from previous assessments of ultrasonic vocalisations in vitamin D-deficient rat pups, which did not reveal any alteration at PND0 (Burne et al. 2011). However, this previous study and our own, only characterise a snapshot of ultrasonic vocalisations over the neonatal period. Ultrasonic vocalisations follow a discrete ontogenetic profile of call rates peaking in the first few days and then diminishing over the remainder of the first two weeks of life in mice and rats (Schwarting $\&$ Wöhr 2012). Therefore, a thorough characterisation of the ontogenetic profile of control and vitamin D-deficient
A

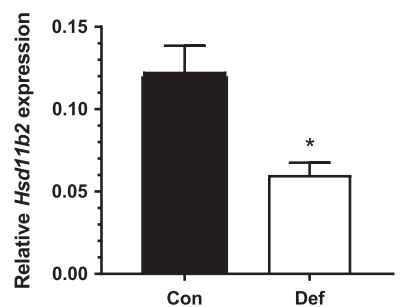

B

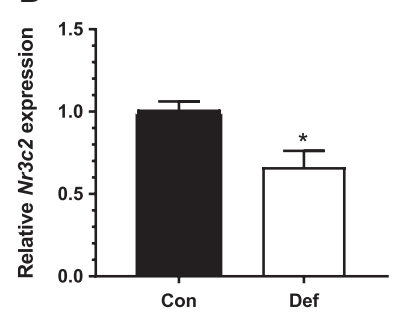

C

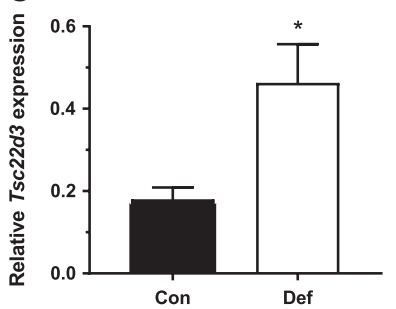

D

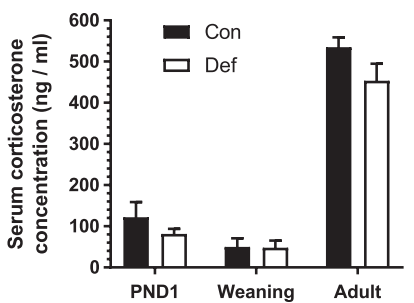

Figure 6

Early life vitamin D deficiency altered some genes involved in glucocorticoid pathways. In postnatal day 1 (PND1) animals, vitamin D deficiency caused a reduction in (A) Hsd11b2 and (B) Nr3c2 levels in the whole brain. There was an (C) increase in Tsc22d3 expression in vitamin D-deficient animals, and (D) no changes in serum corticosterone levels, at PND1, weaning, and in adulthood ( 4 months). Bars show mean + S.E.M., $n=8$ for both control and vitamin D-deficient groups. Significant differences: $t$-test, $* P<0.05$.

$\begin{array}{lr}\text { http://joe.endocrinology-journals.org } & \text { ○ } 2018 \text { Society for Endocrinology } \\ \text { https://doi.org/10.1530/JOE-18-0008 } & \text { Published by Bioscientifica Ltd. } \\ \text { Printed in Great Britain }\end{array}$


pup ultrasonic vocalisations will be useful to understand our current observations.

The significance of the increased call rates may be related to an anxious phenotype in vitamin D-deficient pups, possibly reflecting their exposure to a lower quality of maternal care. Ultrasonic vocalisations are proposed to reflect communication (Ehret 2005, Hofer et al. 2002). In the current study, the altered ultrasonic vocalisations at PND12 were accompanied by a decrease in cortical FOXP2 levels. In rodents, FOXP2 is closely linked with ultrasonic vocalisation production and is important in maternal care interactions such as pup retrieval (Bowers et al. 2013); however, a decrease in FOXP2 is normally associated with reduced ultrasonic vocalisations. Thus, FOXP2 homozygous and heterozygous knockouts, disruption and heterozygous mice on PND8, and heterozygous nonsense FOXP2-mutant mice on PND4 all show reduced call rates (Shu et al. 2005, Fujita et al. 2008, Gaub et al. 2010). The incongruence between ultrasonic vocalisation call rate and FOXP2 levels in our model is currently unclear, but the decreased FOXP2 is consistent with results of our earlier investigations in a mouse model of vitamin $\mathrm{D}$ deficiency (Hawes et al. 2015). FOXP2 has roles beyond communication and is implicated in neurogenesis and neuroplasticity; therefore, there may be additional implications for the FOXP2 reductions elicited by early life vitamin D deficiency.

We have shown that developmental vitamin D deficiency reduces social interaction (social interaction test) and attention switching (object-in-place) in male offspring, without generalised cognitive deficits (novel object recognition), anxiety-like behaviours, anhedonia or neurodevelopmental delay. In rodents, there is spontaneous preference for social interaction with a novel animal compared to an inanimate object (Moy et al. 2004, $\mathrm{Ku}$ et al. 2016). Mice that are vitamin D deficient until parturition (as opposed to weaning in our current study) have previously shown normal levels of social interaction when placed in an open field with another mouse (Harms et al. 2008). However, this approach does not give the test subject the opportunity to preferentially choose between social vs non-social activity. Furthermore, exposure to vitamin D deficiency solely during gestation gives limited context for human maternal vitamin D deficiency, given the relative altricial nature of rodent brains. We also found that vitamin D deficiency produced discrete cognitive changes in offspring. In simple unlearned memory tasks (object recognition), vitamin D-deficient animals perform normally. However, in the more demanding object-inplace testing, vitamin D-deficient offspring show a deficit in change detection compared to controls. A previous study investigating prenatal vitamin $\mathrm{D}$ deficiency in rats also showed subtle changes in novelty detection, a lack of interest in exploration and a lack of habituation as shown in the hole-board habituation task (Becker et al. 2005). These findings are broadly consistent with vitamin D status in pregnant women negatively correlating with offspring attention switching (Whitehouse et al. 2013). While the elevated plus maze test was unsuccessful for assessing anxiety behaviours in the present study, it did enable us to demonstrate increased self-grooming (a measure of repetitive behaviour (for review see Kalueff et al.2016)) in offspring that had been exposed to vitamin D deficiency in early life.

Changes in brain gene expression indicate that vitamin D plays an important role in neurotransmitter signalling and synthesis. In PND1 animals, the reduced expression of Gad1 provides evidence for the role in vitamin D in GABA system regulation, which is supported by similar changes in adult mice, which are vitamin D deficient (Groves et al. 2013). We also observed reductions of Drd2 expression in whole brain lysates on PND1 and in the cerebellum in adult vitamin D-deficient animals. This supports a restricted role for vitamin $\mathrm{D}$ in the development of dopaminergic systems in the brain (Cui et al. 2010) and is congruent with previous studies reporting that vitamin $\mathrm{D}$ deficiency does not necessarily result in widespread changes in dopamine receptor levels in male offspring, despite changes in dopamine turnover (Kesby et al. 2009, 2012). Limited differences were evident in the HPA axis, with changes at PND1 suggesting increased exposure of the neonatal brain to glucocorticoids. This supports previous work in a mouse model of vitamin D deficiency, which demonstrated increased placental transfer and exposure of the foetal brain to glucocorticoids in late gestation (Tesic et al. 2015). However, in this current study, there were no significant differences in offspring circulating corticosterone or HPA axis-related gene expression at other time points, which likely indicates that the adult HPA axis does not contribute to the behavioural phenotype.

Overall, the traits we have observed in male rats exposed to vitamin $\mathrm{D}$ deficiency in early life are suggestive of an ASD-like phenotype. While more extensive characterisation is required to confirm this, placing our data into the context of rodent models of ASD reveals some similarities in altered vocalisations, social, memory and learning parameters and grooming behaviours. Reductions in the initiation and maintenance of social interactions are common among children with ASD. Recent studies have also shown associations with maternal vitamin D 
deficiency and poor language and social responsiveness (Vinkhuyzen et al. 2018) and poor attention switching (Whitehouse et al. 2013). Furthermore, change and novelty detection are impaired in children with autism (Bomba \& Pang 2004) and adults show impairments in explicit (but not implicit) object memory location (Ring et al. 2015). Studies mostly identify reduced ultrasonic vocalisation in rodent models of ASD (Scattoni et al. 2009). However, Schmeisser et al. (2012) reported significantly increased call rate among female ProSAP1/Shank2-/mice compared to wild-type controls during free social interactions. The communication difficulties observed in children and adults with ASD vary considerably between individuals, from those with language learning difficulties to those with pragmatic oddities, such as those with excessive talking (Whitehouse et al. 2010). We note that the epidemiological findings linking early vitamin D deficiencies with ASD traits in children (Vinkhuyzen et al. 2018) have reported a link with pragmatic language difficulties.

ASDs are commonly associated with changes in brain anatomy. While not a specific feature, enlarged lateral ventricles are common in autistic children along with increase of overall brain volume (Palmen et al. 2005, Vidal et al. 2008). The significant enlargement in lateral ventricle volume in our male rats exposed to vitamin D deficiency is consistent with an autism-like phenotype (Eyles et al. 2003) and the neurogenic role of vitamin D (Cui et al. 2007) documented in previous literature. However, because enlarged lateral ventricles are common in a variety of neurodevelopmental disorders, the direct implication this has for brain function is unclear. Furthermore, the enlargement of lateral ventricles is not overtly detrimental in our model, as the behavioural phenotype is not extreme. This implies that plasticity of the brain may compensate in part for early life vitamin D deficiency. Interpreting the changes in Drd2 expression in the cerebellum of vitamin D-deficient animals is limited by the poor understanding of dopamine in the cerebellum, particularly with regard to autism (Fatemi et al. 2012). Similarly, interpreting the reduction in GRIN2B in the mesencephalon is difficult, but worth noting especially given the reported role of NMDA receptor dysfunction in autism (Lee et al. 2015), and the findings that GRIN2B alleles and de novo mutations are associated with schizophrenia and autism (Tarabeux et al. 2011).

Several phenotypic outcomes are most prominent in female vitamin D-deficient offspring. Therefore our study, which was limited to phenotyping male rats, cannot detect changes in some dopamine-mediated behaviours and receptor levels, which are only altered in female offspring (Kesby et al. 2009). This may explain why we did not observe changes in TH staining in the SNpc, which occurs most prominently in female offspring in mice (Hawes et al. 2015).

Our results show that early life vitamin D deficiency elicits changes in maternal care, and in the offspring, alters ultrasonic vocalisations and induces adverse neuropsychiatric outcomes. These finding reinforce the importance of early life vitamin D for optimal neurodevelopment, but it can be attributed not only to direct effects of vitamin $\mathrm{D}$ on the developing brain, but also to indirect pathways such as maternal care and early life glucocorticoid exposure. Furthermore, the behavioural and anatomical phenotype of adult male offspring rats exposed to early life vitamin D exposure is broadly consistent with ASD-like traits. This indicates that vitamin D deficiency may play a mechanistic, and not purely associative, role in the developmental origins of ASD. Therefore, vitamin D level monitoring and appropriate supplementation should be a continually important consideration in antenatal care, due to implications for maternal behaviour, foetal neurodevelopment and later neuropsychiatric outcomes.

\section{Supplementary data}

This is linked to the online version of the paper at https://doi.org/10.1530/ JOE-18-0008.

\section{Declaration of interest}

The authors declare that there is no conflict of interest that could be perceived as prejudicing the impartiality of the research reported.

\section{Funding}

This work was funded by The Ada Bartholomew Fund, The University of Western Australia. The authors acknowledge the facilities, and the scientific and technical assistance of the National Imaging Facility at the Centre for Microscopy, Characterisation \& Analysis, The University of Western Australia, facilities funded by the University, State and Commonwealth Governments. A J O W is funded by a Senior Research Fellowship from the National Health and Medical Research Council (APP1077966). M W C is affiliated to Metabolomics Australia, University of Western Australia, Perth, Western Australia, Australia. This was supported by infrastructure funding from the Western Australian State Government in partnership with the Australian Federal Government, through Bioplatforms Australia and the National Collaborative Research Infrastructure Strategy (NCRIS). http://joe.endocrinology-journals.org
https://doi.org/10.1530/JOE-18-0008 (c) 2018 Society for Endocrinology Published by Bioscientifica Ltd. Printed in Great Britain 


\section{References}

Becker A, Eyles DW, McGrath JJ \& Grecksch G 2005 Transient prenatal vitamin D deficiency is associated with subtle alterations in learning and memory functions in adult rats. Behavioural Brain Research 161 306-312. (https://doi.org/10.1016/j.bbr.2005.02.015)

Bomba MD \& Pang EW 2004 Cortical auditory evoked potentials in autism: a review. International Journal of Psychophysiology 53 161-169. (https://doi.org/10.1016/j.ijpsycho.2004.04.001)

Bowers JM, Perez-Pouchoulen M, Edwards NS \& McCarthy MM 2013 Foxp2 mediates sex differences in ultrasonic vocalization by rat pups and directs order of maternal retrieval. Journal of Neuroscience $\mathbf{3 3}$ 3276-3283. (https://doi.org/10.1523/JNEUROSCI.0425-12.2013)

Bridges RS 2016 Long-term alterations in neural and endocrine processes induced by motherhood in mammals. Hormones and Behavior $\mathbf{7 7}$ 193-203. (https://doi.org/10.1016/j.yhbeh.2015.09.001)

Burne THJ, O'Loan J, Splatt K, Alexander S, McGrath JJ \& Eyles DW 2011 Developmental vitamin D (DVD) deficiency alters pup-retrieval but not isolation-induced pup ultrasonic vocalizations in the rat. Physiology and Behavior 102 201-204. (https://doi.org/10.1016/j. physbeh.2010.11.006)

Capone F, Bonsignore LT \& Cirulli F 2005 Methods in the analysis of maternal behavior in the rodent. Current Protocols in Toxicology Chapter 13 Unit13.9. (https://doi.org/10.1002/0471140856.tx1309s26)

Clarke MW, Tuckey RC, Gorman S, Holt B \& Hart PH 2013 Optimized 25-hydroxyvitamin D analysis using liquid-liquid extraction with 2D separation with LC/MS/MS detection, provides superior precision compared to conventional assays. Metabolomics 9 1031-1040. (https:// doi.org/10.1007/s11306-013-0518-9)

Cottrell EC \& Seckl JR 2009 Prenatal stress, glucocorticoids and the programming of adult disease. Frontiers in Behavioral Neuroscience 319. (https://doi.org/10.3389/neuro.08.019.2009)

Cui X, McGrath JJ, Burne THJ, Mackay-Sim A \& Eyles DW 2007 Maternal vitamin $\mathrm{D}$ depletion alters neurogenesis in the developing rat brain. International Journal of Developmental Neuroscience 25 227-232. (https://doi.org/10.1016/j.ijdevneu.2007.03.006)

Cui X, Pelekanos M, Burne THJ, McGrath JJ \& Eyles DW 2010 Maternal vitamin D deficiency alters the expression of genes involved in dopamine specification in the developing rat mesencephalon. Neuroscience Letters 486 220-223. (https://doi.org/10.1016/j. neulet.2010.09.057)

Cui X, Pelekanos M, Liu PY, Burne THJ, McGrath JJ \& Eyles DW 2013 The vitamin D receptor in dopamine neurons; its presence in human substantia nigra and its ontogenesis in rat midbrain. Neuroscience $\mathbf{2 3 6}$ 77-87. (https://doi.org/10.1016/j.neuroscience.2013.01.035)

Curley JP \& Champagne FA 2016 Influence of maternal care on the developing brain: mechanisms, temporal dynamics and sensitive periods. Frontiers in Neuroendocrinology 40 52-66. (https://doi. org/10.1016/j.yfrne.2015.11.001)

Ehret G 2005 Infant rodent ultrasounds - a gate to the understanding of sound communication. Behavior Genetics 35 19-29. (https://doi. org/10.1007/s10519-004-0853-8)

Eyles D, Brown J, Mackay-Sim A, McGrath J \& Feron F 2003 Vitamin D3 and brain development. Neuroscience 118 641-653. (https://doi. org/10.1016/S0306-4522(03)00040-X)

Eyles DW, Feron F, Cui X, Kesby JP, Harms LH, Ko P, McGrath JJ \& Burne THJ 2009 Developmental vitamin D deficiency causes abnormal brain development. Psychoneuroendocrinology 34 (Supplement 1) S247-S257. (https://doi.org/10.1016/j.psyneuen.2009.04.015)

Eyles D, Burne T \& McGrath J 2011 Vitamin D in fetal brain development. Seminars in Cell and Developmental Biology 22 629-636. (https://doi.org/10.1016/j.semcdb.2011.05.004)

Fatemi SH, Aldinger KA, Ashwood P, Bauman ML, Blaha CD, Blatt GJ, Chauhan A, Chauhan V, Dager SR, Dickson PE, et al. 2012 Consensus paper: pathological role of the cerebellum in autism. Cerebellum $\mathbf{1 1}$ 777-807. (https://doi.org/10.1007/s12311-012-0355-9)
Fernell E, Barnevik-Olsson M, Bagenholm G, Gillberg C, Gustafsson S \& Saaf M 2010 Serum levels of 25-hydroxyvitamin D in mothers of Swedish and of Somali origin who have children with and without autism. Acta Paediatrica 99 743-747. (https://doi.org/10.1111/j.16512227.2010.01755.x)

Fernell E, Bejerot S, Westerlund J, Miniscalco C, Simila H, Eyles D, Gillberg C \& Humble MB 2015 Autism spectrum disorder and low vitamin D at birth: a sibling control study. Molecular Autism 63. (https://doi.org/10.1186/2040-2392-6-3)

Fisher SE \& Scharff C 2009 FOXP2 as a molecular window into speech and language. Trends in Genetics 25 166-177. (https://doi. org/10.1016/j.tig.2009.03.002)

Fujita E, Tanabe Y, Shiota A, Ueda M, Suwa K, Momoi MY \& Momoi T 2008 Ultrasonic vocalization impairment of Foxp2 (R552H) knockin mice related to speech-language disorder and abnormality of Purkinje cells. PNAS 105 3117-3122. (https://doi.org/10.1073/ pnas.0712298105)

Gaub S, Groszer M, Fisher SE \& Ehret G 2010 The structure of innate vocalizations in Foxp2-deficient mouse pups. Genes, Brain and Behavior 9 390-401. (https://doi.org/10.1111/j.1601183X.2010.00570.x)

Groves NJ, Kesby JP, Eyles DW, McGrath JJ, Mackay-Sim A \& Burne TH 2013 Adult vitamin D deficiency leads to behavioural and brain neurochemical alterations in C57BL/6J and BALB/c mice. Behavioural Brain Research 241 120-131. (https://doi.org/10.1016/j.bbr.2012.12.001)

Harms LR, Eyles DW, McGrath JJ, Mackay-Sim A \& Burne THJ 2008 Developmental vitamin D deficiency alters adult behaviour in 129/SvJ and C57BL/6J mice. Behavioural Brain Research 187 343-350. (https:// doi.org/10.1016/j.bbr.2007.09.032)

Hawes JE, Tesic D, Whitehouse AJ, Zosky GR, Smith JT \& Wyrwoll CS 2015 Maternal vitamin D deficiency alters fetal brain development in the BALB/c mouse. Behavioural Brain Research 286 192-200. (https:// doi.org/10.1016/j.bbr.2015.03.008)

Hofer MA, Shair HN \& Brunelli SA 2002 Ultrasonic vocalizations in rat and mouse pups. Current Protocols in Neuroscience Chapter 8 Unit8.14. (https://doi.org/10.1002/0471142301.ns0814s17)

Holmes MC \& Seckl JR 2006 The role of 11beta-hydroxysteroid dehydrogenases in the brain. Molecular and Cellular Endocrinology 248 9-14. (https://doi.org/10.1016/j.mce.2005.12.002)

Holmes MC, Sangra M, French KL, Whittle IR, Paterson J, Mullins JJ \& Seckl JR 2006 11beta-Hydroxysteroid dehydrogenase type 2 protects the neonatal cerebellum from deleterious effects of glucocorticoids. Neuroscience 137 865-873. (https://doi.org/10.1016/j. neuroscience.2005.09.037)

Kalueff AV, Stewart AM, Song C, Berridge KC, Graybiel AM \& Fentress JC 2016 Neurobiology of rodent self-grooming and its value for translational neuroscience. Nature Reviews Neuroscience 17 45-59. (https://doi.org/10.1038/nrn.2015.8)

Kesby JP, Burne TH, McGrath JJ \& Eyles DW 2006 Developmental vitamin D deficiency alters MK 801-induced hyperlocomotion in the adult rat: an animal model of schizophrenia. Biological Psychiatry 60 591-596. (https://doi.org/10.1016/j.biopsych.2006.02.033)

Kesby JP, Cui X, Ko P, McGrath JJ, Burne THJ \& Eyles DW 2009 Developmental vitamin D deficiency alters dopamine turnover in neonatal rat forebrain. Neuroscience Letters 461 155-158. (https://doi. org/10.1016/j.neulet.2009.05.070)

Kesby JP, O'Loan JC, Alexander S, Deng C, Huang X-F, McGrath JJ, Eyles DW \& Burne TH 2012 Developmental vitamin D deficiency alters MK-801-induced behaviours in adult offspring. Psychopharmacology 220 455-463. (https://doi.org/10.1007/s00213011-2492-0)

Ku KM, Weir RK, Silverman JL, Berman RF \& Bauman MD 2016 Behavioral phenotyping of juvenile Long-Evans and SpragueDawley rats: implications for preclinical models of autism spectrum disorders. PLOS ONE 11 e158150. (https://doi.org/10.1371/journal. pone.0158150) 
Kwon HJ 2016 Vitamin D receptor deficiency impairs inner ear development in zebrafish. Biochemical and Biophysical Research Communications 478 994-998. (https://doi.org/10.1016/j. bbrc.2016.08.070)

Lee E-J, Choi SY \& Kim E 2015 NMDA receptor dysfunction in autism spectrum disorders. Current Opinion in Pharmacology 20 8-13. (https:// doi.org/10.1016/j.coph.2014.10.007)

McGrath J, Saari K, Hakko H, Jokelainen J, Jones P, Järvelin M-R, Chant D \& Isohanni M 2004 Vitamin D supplementation during the first year of life and risk of schizophrenia: a Finnish birth cohort study. Schizophrenia Research 67 237-245. (https://doi.org/10.1016/j. schres.2003.08.005)

McGrath JJ, Eyles DW, Pedersen CB, Anderson C, Ko P, Burne TH, Norgaard-Pedersen B, Hougaard DM \& Mortensen PB 2010 Neonatal vitamin D status and risk of schizophrenia: a population-based casecontrol study. Archives of General Psychiatry 67 889-894. (https://doi. org/10.1001/archgenpsychiatry.2010.110)

Meaney MJ, Diorio J, Francis D, Widdowson J, LaPlante P, Caldji C, Sharma S, Seckl JR \& Plotsky PM 1996 Early environmental regulation of forebrain glucocorticoid receptor gene expression: implications for adrenocortical responses to stress. Developmental Neuroscience $\mathbf{1 8}$ 49-72. (https://doi.org/10.1159/000111395)

Moy S, Nadler J, Perez A, Barbaro R, Johns J, Magnuson T, Piven J \& Crawley J 2004 Sociability and preference for social novelty in five inbred strains: an approach to assess autistic-like behavior in mice. Genes, Brain and Behavior 3 287-302. (https://doi.org/10.1111/j.16011848.2004.00076.x)

Numan M 2007 Motivational systems and the neural circuitry of maternal behavior in the rat. Developmental Psychobiology 49 12-21. (https://doi.org/10.1002/dev.20198)

Palmen SJ, Hulshoff Pol HE, Kemner C, Schnack HG, Durston S, Lahuis BE, Kahn RS \& Van Engeland H 2005 Increased gray-matter volume in medication-naive high-functioning children with autism spectrum disorder. Psychological Medicine 35 561-570. (https://doi. org/10.1017/S0033291704003496)

Pena CJ \& Champagne FA 2015 Neonatal overexpression of estrogen receptor-alpha alters midbrain dopamine neuron development and reverses the effects of low maternal care in female offspring. Developmental Neurobiology 75 1114-1124. (https://doi.org/10.1002/ dneu.22206)

Ring M, Gaigg SB \& Bowler DM 2015 Object-location memory in adults with autism spectrum disorder. Autism Research 8 609-619. (https:// doi.org/10.1002/aur.1478)

Robinson M, Whitehouse AJ, Newnham JP, Gorman S, Jacoby P, Holt BJ, Serralha M, Tearne JE, Holt PG, Hart PH, et al. 2014 Low maternal serum vitamin D during pregnancy and the risk for postpartum depression symptoms. Archives of Women's Mental Health 17 213-219. (https://doi.org/10.1007/s00737-014-0422-y)

Scattoni ML, Crawley J \& Ricceri L 2009 Ultrasonic vocalizations: a tool for behavioural phenotyping of mouse models of neurodevelopmental disorders. Neuroscience and Biobehavioral Reviews 33 508-515. (https://doi.org/10.1016/j.neubiorev.2008.08.003)

Schmeisser MJ, Ey E, Wegener S, Bockmann J, Stempel AV, Kuebler A, Janssen A-L, Udvardi PT, Shiban E, Spilker C, et al. 2012 Autistic-like behaviours and hyperactivity in mice lacking ProSAP1/Shank2. Nature 486 256-260. (https://doi.org/10.1038/nature11015)

Schwarting RKW \& Wöhr M 2012 On the relationships between ultrasonic calling and anxiety-related behavior in rats. Brazilian Journal of Medical and Biological Research 45 337-348. (https://doi. org/10.1590/S0100-879X2012007500038)
Shu W, Cho JY, Jiang Y, Zhang M, Weisz D, Elder GA, Schmeidler J, De Gasperi R, Sosa MAG, Rabidou D, et al. 2005 Altered ultrasonic vocalization in mice with a disruption in the Foxp2 gene. PNAS 102 9643-9648. (https://doi.org/10.1073/pnas.0503739102)

Tarabeux J, Kebir O, Gauthier J, Hamdan FF, Xiong L, Piton A, Spiegelman D, Henrion E, Millet B, Fathalli F, et al. 2011 Rare mutations in N-methyl-D-aspartate glutamate receptors in autism spectrum disorders and schizophrenia. Translational Psychiatry 1 e55. (https://doi.org/10.1038/tp.2011.52)

Tesic D, Hawes JE, Zosky GR \& Wyrwoll CS 2015 Vitamin D deficiency in BALB/c mouse pregnancy increases placental transfer of glucocorticoids. Endocrinology 156 3673-3679. (https://doi. org/10.1210/en.2015-1377)

Vaziri F, Nasiri S, Tavana Z, Dabbaghmanesh MH, Sharif F \& Jafari P 2016 A randomized controlled trial of vitamin $\mathrm{D}$ supplementation on perinatal depression: in Iranian pregnant mothers. BMC Pregnancy and Childbirth 16 239. (https://doi.org/10.1186/s12884-016-1024-7)

Vidal CN, Nicolson R, Boire J-Y, Barra V, DeVito TJ, Hayashi KM, Geaga JA, Drost DJ, Williamson PC, Rajakumar N, et al. 2008 Threedimensional mapping of the lateral ventricles in autism. Psychiatry Research: Neuroimaging 163 106-115. (https://doi.org/10.1016/j. pscychresns.2007.11.002)

Vinkhuyzen AA, Eyles DW, Burne TH, Blanken LM, Kruithof CJ, Verhulst F, Jaddoe VW, Tiemeier H \& McGrath JJ 2018 Gestational vitamin D deficiency and autism-related traits: the Generation R Study. Molecular Psychiatry 23 240-246. (https://doi.org/10.1038/ mp.2016.213)

Vuillermot S, Luan W, Meyer U \& Eyles D 2017 Vitamin D treatment during pregnancy prevents autism-related phenotypes in a mouse model of maternal immune activation. Molecular Autism 89. (https:// doi.org/10.1186/s13229-017-0125-0)

Weaver I, Cervoni N, Champagne F, D'Alessio A, Sharma S, Seckl J, Dymov S, Szyf M \& Meaney M 2004 Epigenetic programming by maternal behavior. Nature Neuroscience 7 847-854. (https://doi. org/10.1038/nn1276)

Wharfe MD, Mark PJ, Wyrwoll CS, Smith JT, Yap C, Clarke MW \& Waddell BJ 2016 Pregnancy-induced adaptations of the central circadian clock and maternal glucocorticoids. Journal of Endocrinology 228 135-147. (https://doi.org/10.1530/JOE-15-0405)

Whitehouse AJO, Coon H, Miller J, Salisbury B \& Bishop DVM 2010 Narrowing the broader autism phenotype. Autism 14 559-574. (https://doi.org/10.1177/1362361310382107)

Whitehouse AJ, Holt BJ, Serralha M, Holt PG, Kusel MM \& Hart PH 2012 Maternal serum vitamin D levels during pregnancy and offspring neurocognitive development. Pediatrics 129 485-493. (https://doi. org/10.1542/peds.2011-2644)

Whitehouse AJ, Holt BJ, Serralha M, Holt PG, Hart PH \& Kusel MM 2013 Maternal vitamin D levels and the autism phenotype among offspring. Journal of Autism and Developmental Disorders 43 1495-1504. (https://doi.org/10.1007/s10803-012-1676-8)

Williams JA, Romero VC, Clinton CM, Vazquez DM, Marcus SM, Chilimigras JL, Hamilton SE, Allbaugh LJ, Vahratian AM, Schrader RM, et al. 2016 Vitamin D levels and perinatal depressive symptoms in women at risk: a secondary analysis of the mothers, omega-3, and mental health study. BMC Pregnancy and Childbirth 16 203. (https://doi.org/10.1186/s12884-016-0988-7)

Wyrwoll CS \& Holmes MC 2012 Prenatal excess glucocorticoid exposure and adult affective disorders: a role for serotonergic and catecholamine pathways. Neuroendocrinology 95 47-55. (https://doi. org/10.1159/000331345)

Received in final form 8 February 2018

Accepted 28 February 2018 http://joe.endocrinology-journals.org

https://doi.org/10.1530/JOE-18-0008
(C) 2018 Society for Endocrinology Published by Bioscientifica Ltd. Printed in Great Britain 